\title{
Numerical Study of the Steady-State Subchannel Test-Case with NEPTUNE_CFD for the OECD/NRC NUPEC PSBT Benchmark
}

\author{
C. Baudry, M. Guingo, A. Douce, J. Laviéville, S. Mimouni, and M. Boucker \\ EDF RઐD, Fluid Dynamics, Power Generation and Environment Department-6, Quai Watier 78401 Chatou, France
}

Correspondence should be addressed to M. Guingo, mathieu.guingo@edf.fr

Received 30 March 2012; Accepted 27 July 2012

Academic Editor: Diana Cuervo

Copyright () 2012 C. Baudry et al. This is an open access article distributed under the Creative Commons Attribution License, which permits unrestricted use, distribution, and reproduction in any medium, provided the original work is properly cited.

The multifield computational fluid dynamics (CFD) code NEPTUNE_CFD is applied to carry out a numerical study of the steadystate subchannel test-case of the OECD/NRC NUPEC PWR subchannel and bundle tests (PSBTs) international benchmark, focusing on the simulation of a subset of five selected experimental runs of the centered subchannel configuration. First, using a standard choice for the physical models and a constant, predetermined bubble diameter, the calculated void fraction is compared to experimental data. Besides, the mesh sensitivity of the calculated void fraction is investigated by performing simulations of three grid levels, and the propagation of the experimental uncertainties on the input parameters of the simulations is also studied. Last, calculation results with devoted models for the bubble-size distribution are analyzed. Their impact is visible on the subcooled run, giving void fraction closer to experiments than those obtained with a fixed bubble-size. Void-fraction distribution with bubble-size models is also shown to come closer to experiment for another run with a higher equilibrium quality.

\section{Introduction}

The OECD/NRC PWR subchannel and bundle Tests (PSBT) benchmark was an international project endorsed by the OECD/NEA (Organisation for Economic Co-operation and Development/Nuclear Energy Agency) and supported by US NRC (United States National Regulatory Commission) and METI (Japanese Ministry of Economy, Trade and Industry), in which a large experimental database of void-fraction measurements performed at NUPEC (Nuclear Power Engineering Corporation) under PWR (Pressurized Water Reactor) thermal-hydraulic conditions in different geometric configurations (different types of isolated subchannels or rod bundle) has been made available to the participants for numerical simulation. One of the purposes of this benchmark is to provide experimental data that can be used for the validation of numerical models of void-fraction distribution over a wide range of operating conditions, and for the development of novel approaches. PSBT was not a blind benchmark, in the sense of the experimental value of the variables of interest were provided to the participants. The benchmark was organized in two phases; the first focusing on a void-distribution benchmark while the topic of the second was the departure from nucleate boiling (DNB) phenomenon. More details on the benchmark organization can be found at [1]. Each phase encompassed several exercises: the current paper focuses on the simulation of the steady-state subchannel exercise of phase I (i.e., Exercise I-1). For each simulated run of this exercise, three main results were asked from the participants.

(i) A numerical calculation of the cross-section void fraction at a given elevation, to be compared to experimental data.

(ii) A 2D view of the void-fraction distribution in this section. Ideally, this result could also be compared to an experimental view obtained by chromotomography. However, this comparison was proven difficult due in particular to the fairly low resolution of the experimental view. Therefore, in the following, only one of these experimental views will be used for comparison with numerical simulations.

(iii) The evolution of the cross-section averaged void fraction with respect to the elevation. No experimental data was available for this result. However, it seemed interesting to analyze how the different 
codes predicted, for instance, the transition to fullydeveloped subcooled boiling for some of the runs.

This paper aims at presenting and analyzing simulations carried out with the multifield computational fluid dynamics (CFD) code NEPTUNE_CFD [2] for Exercise I-1. Following the NEA/CSNI best practice guidelines [3], a mesh sensitivity analysis is performed on three grid refinements, and the influence of the experimental uncertainties on the numerical results is assessed. As a first step, the standard set of parameters of the code is applied, with in particular the use of a second-order (Reynolds stress) turbulence model, as well as a constant, predetermined bubble diameter. In the last part of the paper, the impact of more detailed descriptions of the bubble-size distribution is presented.

\section{Experimental Configuration of the Steady-State Subchannel Exercise}

The test facility of the steady-state subchannel exercise represents one of the subchannel types found in a PWR assembly. The effective heated length is $1.555 \mathrm{~m}$, while the measurement of the void fraction takes place at $1.4 \mathrm{~m}$ from the bottom of the heated section. The external diameter of the rod is $9.5 \mathrm{~mm}$; the rod pitch and the rod gap measure, respectively, $12.6 \mathrm{~mm}$ and $3.1 \mathrm{~mm}$. The heating power is uniformly distributed. Additional details about the experimental apparatus may be found in [4]. The void fraction is measured by using the chromotomography (CT) technique, which also gives the local distribution of the time-averaged void fraction at the measuring section [5]. The initial set of experimental runs of Exercise I-1 counted approximately 40 runs, taking place in different subchannel types (center, center with a guide tube, side and corner). However, after discussion between participants and PSBT organizers, five runs have been selected to be more precisely analyzed:

(i) the run whose operating conditions are the closest to PWR normal conditions (reference 1.2211),

(ii) two runs with a higher inlet temperature and a relatively low wall heat flux (references 1.2223 and 1.2237),

(iii) two runs differing only by the value of the inlet temperature (references 1.4325 and 1.4326), with a lower heat flux and a lower pressure than run 1.2211. Run 1.4325 was also chosen due to its particular voidfraction distribution at the measuring section, mainly located in the non-heated corners of the domain.

The value of the controlling parameters of the runs and the cross-section averaged void-fraction measurements are summarized in Table 1. Furthermore, the estimated uncertainties on the flow parameters and on the voidfraction measurement provided by the experimentalists are given in Table 2. It can be observed that run 1.2211 is the only selected run in subcooled conditions in the whole subchannel (with a negative thermal equilibrium quality at the measuring section).
TABLE 1: Characteristics of the five selected test-cases. In bold font, the run whose condition are the closest to PWR normal conditions.

\begin{tabular}{|c|c|c|c|c|c|}
\hline & 1.2211 & 1.2223 & 1.2237 & 1.4325 & 1.4326 \\
\hline Outlet pressure (bar) & 147.2 & 147.2 & 147.4 & 98.4 & 98.2 \\
\hline Inlet temperature $(\mathrm{K})$ & 295.4 & 319.6 & 329.6 & 253.6 & 268.8 \\
\hline $\begin{array}{l}\text { Inlet mass flow rate } \\
\left(\mathrm{kg} \cdot \mathrm{m}^{-2} \cdot \mathrm{s}^{-1}\right)\end{array}$ & 3030.6 & 3030.6 & 3036.1 & 1397.2 & 1394.4 \\
\hline Wall heat flux (kW) & 90 & 69.8 & 60 & 59.8 & 59.8 \\
\hline Equilibrium quality & -0.04 & 0.04 & 0.08 & 0.05 & 0.11 \\
\hline Averaged void fraction & 0.04 & 0.31 & 0.44 & 0.34 & 0.53 \\
\hline $\begin{array}{l}\text { Averaged fluid density } \\
\left(\mathrm{kg} \cdot \mathrm{m}^{-3}\right)\end{array}$ & 610 & 456 & 390 & 478 & 353 \\
\hline
\end{tabular}

TABLe 2: Given experimental uncertainties on the controlling parameters of the test-case and on the void-fraction measurements.

\begin{tabular}{lc}
\hline & Estimated exp. uncertainties $(1 \sigma)$ \\
\hline Pressure & $1 \%$ \\
Inlet temperature & $1 \mathrm{~K}$ \\
Mass flow rate & $1.5 \%$ \\
Wall heat flux & $1 \%$ \\
Averaged void fraction & 0.03 \\
\hline
\end{tabular}

\section{The NEPTUNE_CFD Code}

3.1. Main Features of the Code. NEPTUNE_CFD is a 3D, multifield CFD code developed in the framework of the NEPTUNE project, financially supported by CEA (Commissariat à l'Énergie Atomique et aux Énergies Alternatives), EDF, IRSN (Institut de Radioprotection et de Sûreté Nucléaire) and AREVA-NP. It is mainly devoted to the study and the simulation of nuclear reactor applications involving multiphase flows, such as two-phase pressurized thermal shock (PTS) and departure from nucleate boiling (DNB) applications. The need to simulate PTS applications have led in particular to the development and the numerical implementation of specific methods of interface detection for free surface flows [6]. The code follows the classical multifield one-pressure formulation [7]. For each phase $k$, the basic set of resolved conservation equations (mass, momentum and total enthalpy denoted $H_{k}$ ) is the following:

$$
\begin{aligned}
& \frac{\partial \alpha_{k} \rho_{k}}{\partial t}+\operatorname{div}\left(\alpha_{k} \rho_{k} \mathbf{U}_{\mathbf{k}}\right)=\Gamma_{k} \\
& \frac{\partial \alpha_{k} \rho_{k} \mathbf{U}_{\mathbf{k}}}{\partial t}+\operatorname{div}\left(\mathbf{U}_{\mathbf{k}} \otimes \alpha_{k} \rho_{k} \mathbf{U}_{\mathbf{k}}\right) \\
& =\operatorname{div}\left(\alpha_{k} \tau_{\mathbf{k}}+\boldsymbol{\Sigma}_{\mathbf{k}}\right)-\alpha_{k} \nabla P+\mathbf{I}_{\mathbf{k}}^{\prime}+\Gamma_{k} \mathbf{U}_{\mathbf{k}}+\alpha_{k} \rho_{k} \mathbf{g}+\alpha_{k} \mathbf{S}_{\mathbf{k}}, \\
& \frac{\partial \alpha_{k} \rho_{k} H_{k}}{\partial t}+\operatorname{div}\left(\alpha_{k} \rho_{k} \mathbf{U}_{\mathbf{k}} H_{k}\right) \\
& =\operatorname{div}\left(\alpha_{k} \lambda_{k} \nabla T_{k}\right)+\operatorname{div}\left(\left(\alpha_{k} \tau_{\mathbf{k}}+\boldsymbol{\Sigma}_{\mathbf{k}}\right) \mathbf{U}_{\mathbf{k}}\right) \\
& +\alpha_{k} \frac{\partial P}{\partial t}+\mathbf{U}_{\mathbf{k}} \cdot \mathbf{I}_{\mathbf{k}}^{\prime}+\alpha_{k} \rho_{k} \mathbf{g} \cdot \mathbf{U}_{\mathbf{k}}+\Gamma_{k} H_{k}+\Pi_{\mathbf{k}}^{\prime}
\end{aligned}
$$


Additionally, the following relation on volume fractions holds:

$$
\sum \alpha_{k}=1
$$

In these equations, $\alpha_{k}$ is the volume fraction, $\rho_{k}$ is the density, $\mathbf{U}_{\mathbf{k}}$ is the velocity, $\tau_{\mathbf{k}}$ and $\boldsymbol{\Sigma}_{\mathbf{k}}$ are, respectively, the laminar and the turbulent stress tensor; $\Gamma_{k}$ is the interfacial mass transfer, $\mathbf{I}_{\mathbf{k}}^{\prime}$ represents the momentum transfer from all the other phases to phase $k, \Pi_{\mathbf{k}}^{\prime}$ represents the heat transfer between phases, $P$ is the pressure, $T_{k}$ is the temperature, and $\lambda_{k}$ is the conductivity. Additional jump relations are supplied for the interfacial transfers.

The spatial discretization is a full unstructured finitevolume approach with a collocated arrangement of allvariables. The numerical algorithm used is a semi-implicit, pressure-based method where the system of equations is solved in two major fractional steps: first, a prediction of the velocities based on the momentum equations; then, the coupling between phase fraction, pressure, and energy through mass and energy equations and a simplified form of momentum equations [8].

3.2. Physical Modeling for the Current Study. The turbulence of the liquid phase is modeled using a second-order, RANS (Reynolds-Averaged Navier-Stokes) model [9] including bubble-induced turbulence effects, whereas a turbulent dispersion model is applied on the gas phase [10]. The interfacial transfer of momentum is considered as the sum of different contributions, namely, the drag force (modeled by using the correlation developed by Ishii and Zuber [11]), the added mass force (by using the expression of Zuber [12]) and the formulation of the lift force proposed by Tomiyama et al. [13]. As a general feature of the NEPTUNE_CFD code, no flow-regime map is used, as the flow is regarded as bubbly.

At the heating wall, the heat transfer model is an extension of the approach of Kurul and Podowski [14], which is often referred to as the RPI (rensselaer polytechnic institute) model and which consists in splitting the heat flux into three terms: one heating the liquid phase in contact with the wall, one responsible for the bubble generation, and the last one arising from the arrival of liquid water at the wall, caused by bubble departure (the so-called "quenching" flux). When the void fraction in the boundary cells is sufficiently high, a fourth flux is introduced to take into account the convective heat transfer transmitted to the vapor. In the bulk, the recondensation model is based on the Ranz-Marshall correlation.

For the first series of calculations, a constant, predetermined diameter for the bubbles has been taken equal to $0.3 \mathrm{~mm}$, based on previous experimental observations carried out in PWR conditions [15]. It can be thus expected for this modeling choice to behave more satisfactorily for runs with a relatively low void fraction (i.e., where coalescence and fragmentation phenomena can be neglected). As a second step, the influence of a more refined description of the bubble-size distribution has been studied by performing simulations using the interfacial area models of Yao and

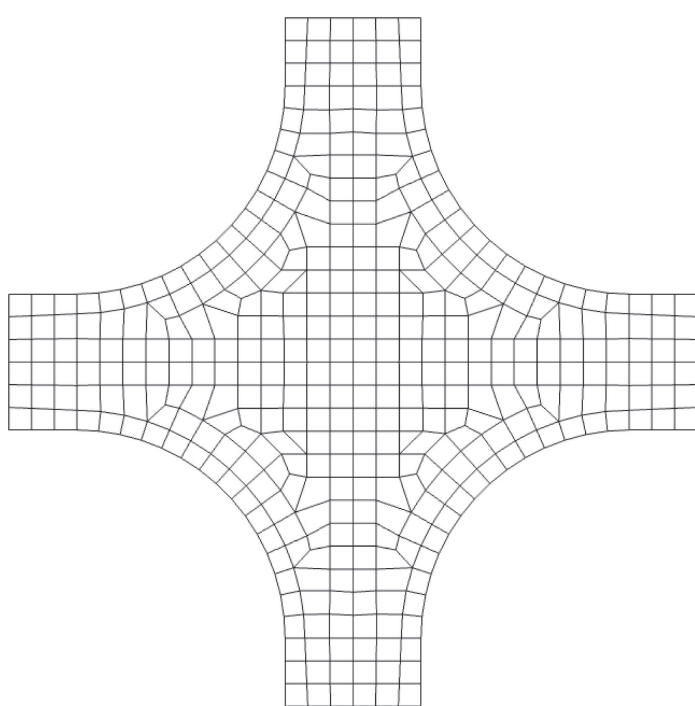

Figure 1: Cross-section view of grid level 1.

TABLE 3: Characteristics of the grids used in the simulations.

\begin{tabular}{lccc}
\hline & Grid level 1 & Grid level 2 & Grid level 3 \\
\hline $\begin{array}{l}\text { Total number of cells } \\
\begin{array}{l}\text { Number of cells in the axial } \\
\text { direction }\end{array}\end{array}$ & 400 & 520 & 520 \\
$\begin{array}{l}\text { Number of cells in } \\
\text { a cross-section }\end{array}$ & 388 & 1160 & 3008 \\
$\begin{array}{l}\text { Cell size in the axial direction } \\
\text { Distance-to-wall of the }\end{array}$ & $4 \mathrm{~mm}$ & $3 \mathrm{~mm}$ & $3 \mathrm{~mm}$ \\
boundary-cell centers & $0.25 \mathrm{~mm}$ & $0.15 \mathrm{~mm}$ & $0.1 \mathrm{~mm}$ \\
\hline
\end{tabular}

Morel [16] and Ruyer and co-workers [17], which have been validated in PWR conditions in a vertical duct geometry.

\section{Computational Strategy}

4.1. Time Convergence. In order to reach the steady state, a transient algorithm is used in NEPTUNE_CFD. The time step chosen is time-dependent, with a maximal CFL number set to 1 for stability reasons and convergence of the iterative numerical algorithm.

4.2. Characteristics of the Grids. Following the NEA/CSNI (Committee on the Safety of Nuclear Installations) best practice guidelines, three grids with different refinements have been used for this study. Their main features are recapitulated in Table 3; cross-section views of the grids are proposed in Figures 1, 2, and 3. The normalized wallnormal distance of the boundary-cells centers ranges from approximately 75 (run 1.4326, grid level 3) to approximately 320 (run 1.2211, grid level 1), supporting the use of a highReynolds formulation of a second-order RANS turbulence model. It can be seen that the refinement factor from grid level 1 to grid level 3 is approximately equal to 3 following two perpendiculars belonging to a cross-section, and 1.3 in the axial direction. 


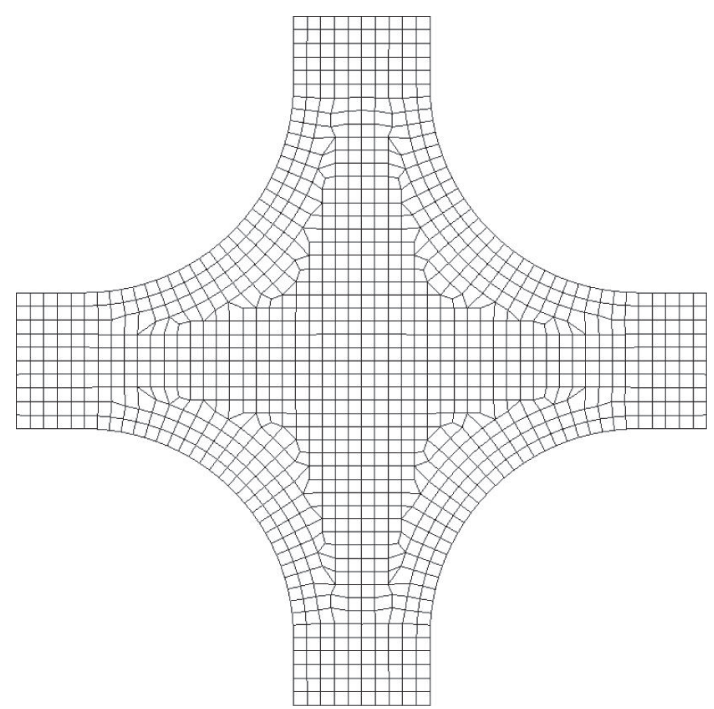

Figure 2: Cross-section view of grid level 2.

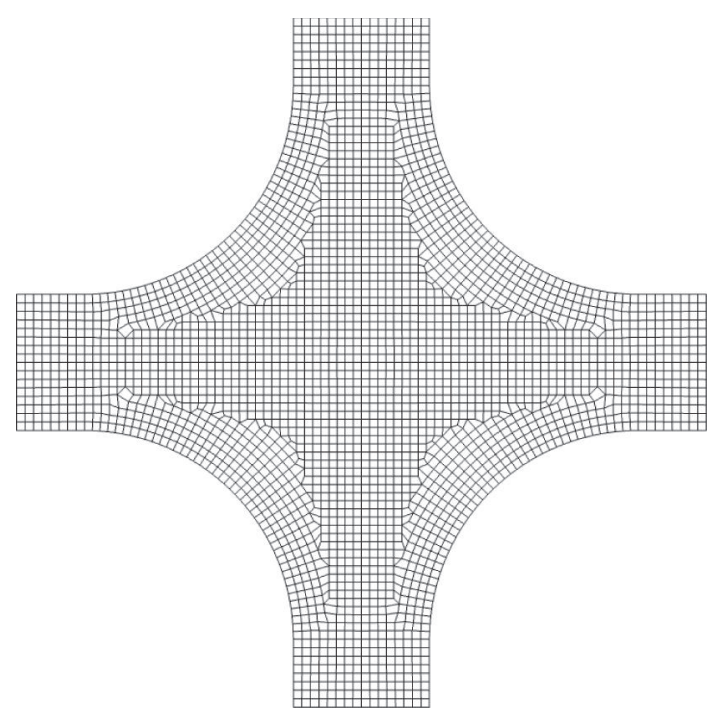

Figure 3: Cross-section view of grid level 3.

4.3. Boundary and Initial Conditions. The profiles of the inlet velocities and turbulent variables (Reynolds stresses and mean dissipation) have been calculated before-hand through devoted calculations, so as to get developed flow profiles. The procedure followed for these calculations amounts to calculating a case without thermal power in an infinite channel of the same cross section; and then selecting the profiles of the variables where they do not vary anymore. The initial conditions for velocities, temperature and turbulent variables are taken equal to the inlet conditions.

\section{Results Obtained with a Constant, Predetermined Bubble Diameter}

5.1. Void Fraction at the Measuring Section. The calculations have been carried out on 36 to 144 cores on the EDF R\&D
TABLE 4: Cross-section averaged void fraction obtained on the three grid levels.

\begin{tabular}{lccccc}
\hline & 1.2211 & 1.2223 & 1.2237 & 1.4325 & 1.4326 \\
\hline Exp. values & 0.04 & 0.31 & 0.44 & 0.34 & 0.53 \\
\hline Grid level 1 & 0.06 & 0.25 & 0.36 & 0.44 & 0.63 \\
Grid level 2 & 0.07 & 0.25 & 0.36 & 0.44 & 0.63 \\
Grid level 3 & 0.07 & 0.25 & 0.36 & 0.44 & 0.63 \\
\hline
\end{tabular}

Ivanhoe cluster (Westmere $2.93 \mathrm{GHz}$ Infiniband). The time to reach the steady state represents approximately 2 to 4 seconds of "physical" time. First, calculations were run under nominal conditions on the three grid levels to investigate the grid sensitivity of the results. The values of the crosssection averaged void fraction at the 1.40 -meter section are summarized in Table 4 . It can be observed that simulations performed on grid level 1 give void-fraction values come very close to those obtained on grid level 3 (the discrepancy is of order of \pm 0.01 ).

Concerning the comparison with the experimental values for the cross-section averaged void fraction:

(i) for run 1.2211 (subcooled), the simulations overestimate the void fraction by 0.03 ; thus, reaching the upper bound of the $1 \sigma$-uncertainty on the voidfraction measurement.

(ii) for runs 1.2223 and 1.2237 (high inlet temperature and low wall heat flux), the simulations underestimate the experimental void fraction by 0.06 to 0.08 ;

(iii) for runs 1.4325 and 1.4326 (low pressure), the void fraction is overestimated by 0.1 .

On average, the deviation between numerical results and experimental data is then of the order of 0.06 void-fraction units; and consequently more visible on the subcooled run (1.2211).

5.2. Axial Evolution of the Flow. The axial evolution of the cross-section averaged void fraction for the five runs are presented from Figures 5, 6, 7, 8, and 9, as well as the axial evolution of the wall temperature at a given location of a heating wall (see Figure 4).

It can be seen that for almost every run (except for the subcooled run 1.2211), vapor is generated right from the start of the heated section. Furthermore, concerning runs $1.2223,1.2237$, and 1.4325 , a change of the slope in the evolution of the mean void fraction is visible, respectively, for an elevation approximately equal to $0.9 \mathrm{~m}, 0.6 \mathrm{~m}$, and $0.9 \mathrm{~m}$. This change occurs at the same elevation as an increase of the wall temperature, indicating the beginning of the fully-developed subcooled boiling (FDB) [18]. Runs 1.4325 and 1.4326 exhibit approximately the same behavior. For instance, for run 1.4325, different regimes are observed:

(i) from the bottom of the subchannel to approximately $0.7 \mathrm{~m}$, the mean void fraction is rising slowly, corresponding to the partial subcooled boiling regime;

(ii) from $0.7 \mathrm{~m}$ up, the void fraction rises more rapidly, corresponding to the FDB regime. 


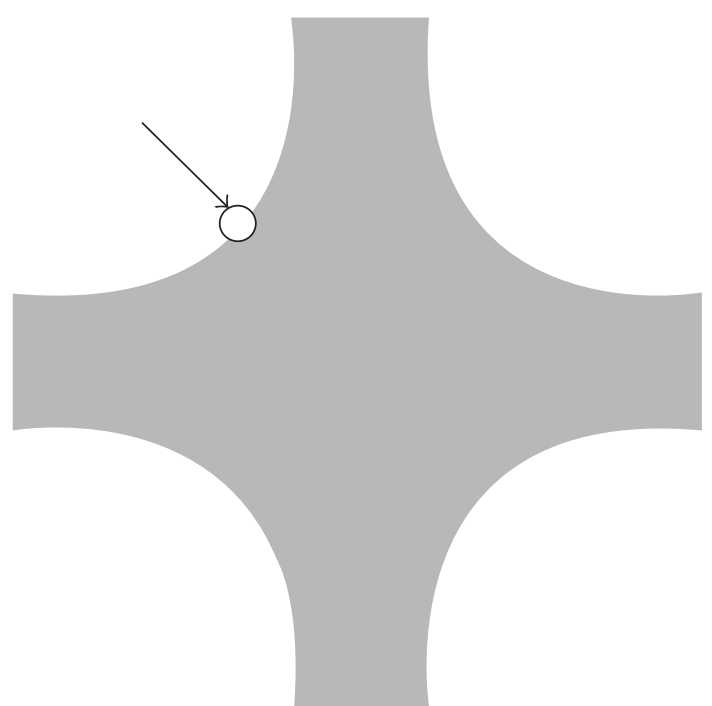

FIGURE 4: Position of the probe monitoring the axial evolution of the wall temperature.

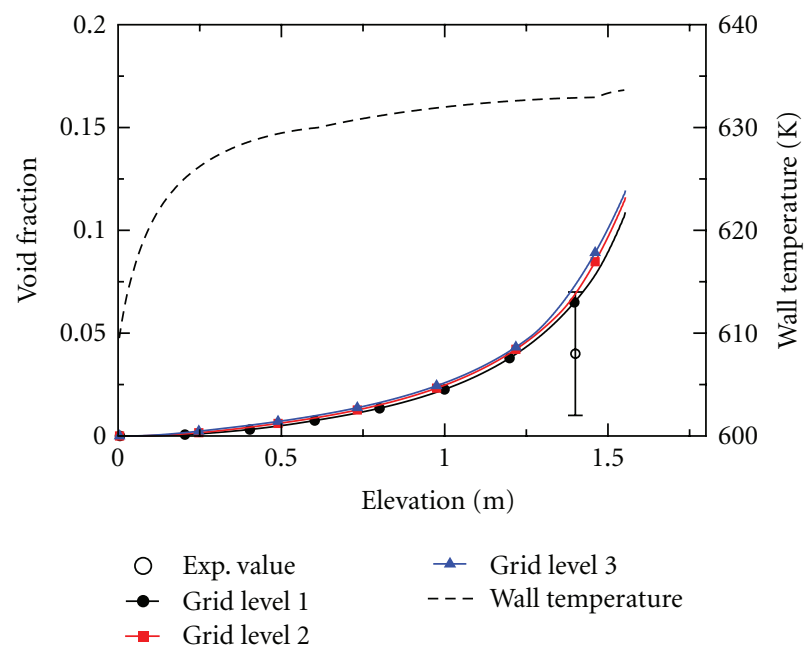

Figure 5: Run 1.2211. Axial evolution of the cross-section averaged void fraction for the 3 grid levels.

(iii) finally, towards the end of the domain, the wall temperature jumps from $605 \mathrm{~K}$ to several thousands Kelvin (not represented): in this region, the calculated near-wall void fraction exceeds 0.8 , which is the threshold value used in the code to switch continuously from the nucleate boiling to a pseudofilm boiling. In this model, the totality of the imposed heat flux is transferred to the vapor (rising its temperature above saturation), therefore, bringing about a drop of the heat transfer coefficient. Let us note that this model is not yet considered as validated.

Furthermore, Figure 10 represents the evolution of the average liquid temperature and of the saturation temperature for run 1.4325. At the end of the domain, the two temperatures

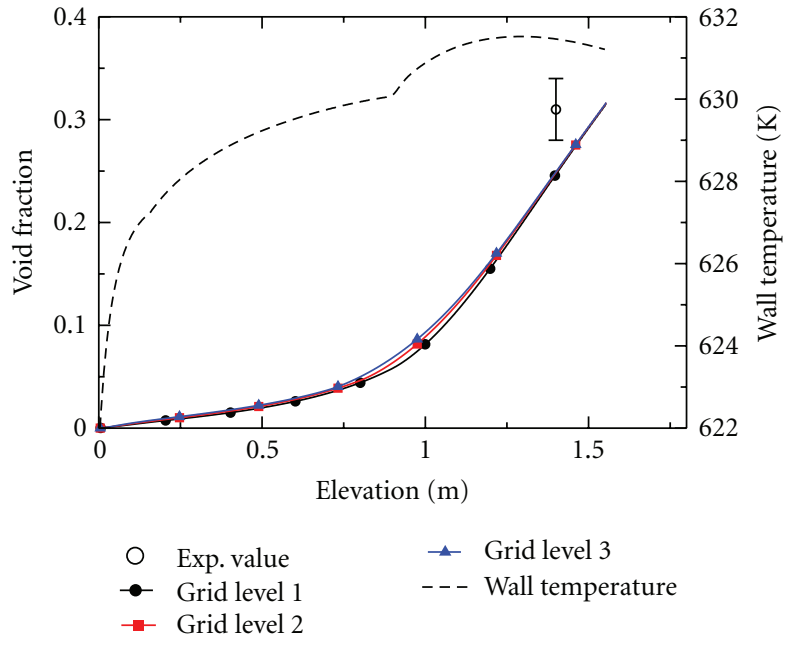

Figure 6: Run 1.2223. Axial evolution of the cross-section averaged void fraction for the 3 grid levels.

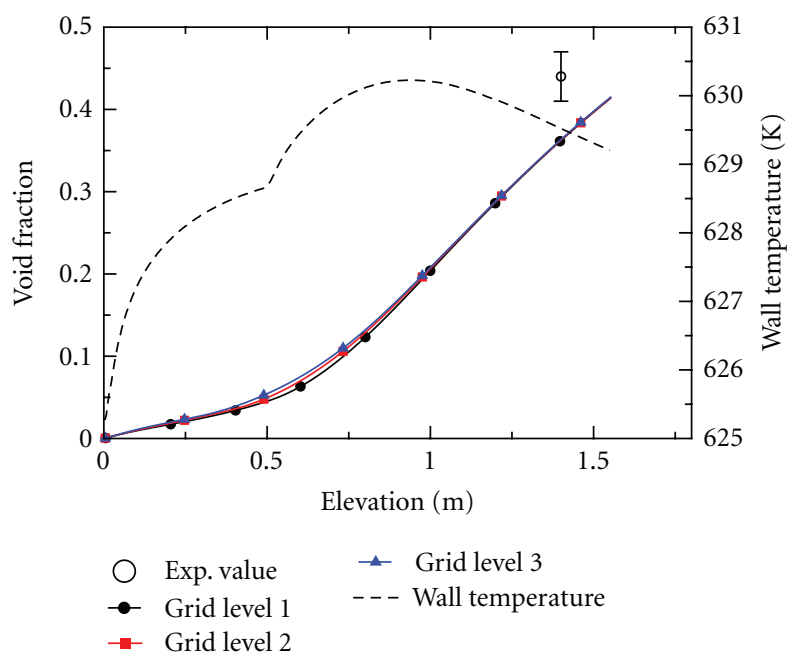

FIGURE 7: Run 1.2237. Axial evolution of the cross-section averaged void fraction for the 3 grid levels.

are almost equal, corresponding to the saturated boiling regime.

5.3. Propagation of the Experimental Uncertainties. As the estimated uncertainties on the controlling parameters of the flow are provided (see Table 2), it is interesting to analyze the effects of these uncertainties on the simulations. For this purpose, a series of calculations has been performed in which one of the controlling parameters is taken equal to its nominal values plus or minus the value of the relative uncertainties, the other parameters remaining fixed to the nominal values. This procedure makes it possible to study the effect of one uncertainty independently from the others. In order to keep a reasonable time-to-result, the coarsest grid has been used (grid level 1). The results obtained for the void fraction are recapitulated in Table 5. 
TABLE 5: Effect of the experimental uncertainties on the calculated void fraction.

\begin{tabular}{|c|c|c|c|c|c|}
\hline & 1.2211 & 1.2223 & 1.2237 & 1.4325 & 1.4326 \\
\hline Exp. values & 0.04 & 0.31 & 0.44 & 0.34 & 0.53 \\
\hline Nominal Calc. values $\left(\alpha_{\text {nom }}\right)$ & 0.07 & 0.25 & 0.36 & 0.44 & 0.64 \\
\hline Pressure $\pm 1 \%$ & $\alpha_{\text {nom }} \pm 0.02$ & $\alpha_{\text {nom }} \pm 0.02$ & $\alpha_{\text {nom }} \pm 0.02$ & $\alpha_{\text {nom }} \pm 0.01$ & $\alpha_{\text {nom }} \pm 0.01$ \\
\hline Inlet Temp. $\pm 1 \mathrm{~K}$ & $\alpha_{\text {nom }} \pm 0.02$ & $\alpha_{\text {nom }} \pm 0.02$ & $\alpha_{\text {nom }} \pm 0.02$ & $\alpha_{\text {nom }} \pm 0.01$ & $\alpha_{\text {nom }} \pm 0.01$ \\
\hline Mass flow rate $\pm 1.5 \%$ & $\alpha_{\text {nom }} \pm 0.01$ & $\alpha_{\text {nom }} \pm 0.01$ & $\alpha_{\text {nom }} \pm 0.01$ & $\alpha_{\text {nom }} \pm 0.01$ & $\alpha_{\text {nom }} \pm 0.01$ \\
\hline Wall heat flux $\pm 1 \%$ & $\alpha_{\text {nom }} \pm 0.01$ & $\alpha_{\text {nom }} \pm 0.01$ & $\alpha_{\text {nom }} \pm 0.01$ & $\alpha_{\text {nom }} \pm 0.01$ & $\alpha_{\text {nom }} \pm 0.01$ \\
\hline
\end{tabular}

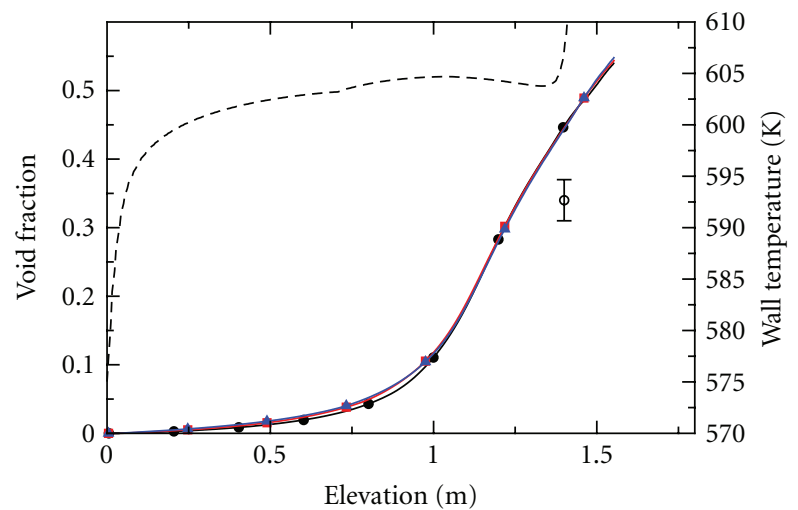

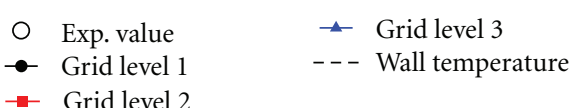

FIGURE 8: Run 1.4325. Axial evolution of the cross-section averaged void fraction for the 3 grid levels.

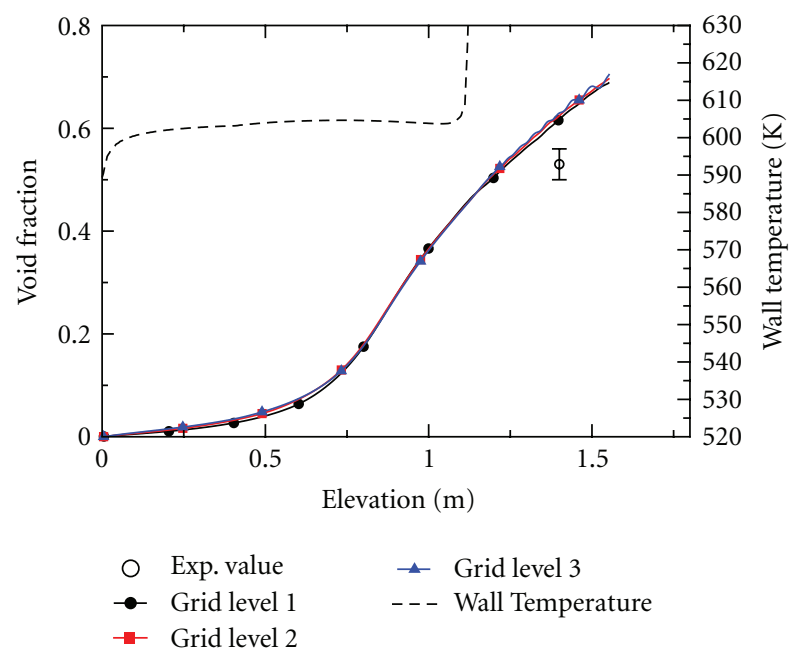

Figure 9: Run 1.4326. Axial evolution of the cross-section averaged void fraction for the 3 grid levels.

These series of calculations show that for a relatively small variation of any parameter, the result on the averaged void fraction is modified by approximately 0.01 , whatever its absolute value. Consequently, the relative impact on the void-fraction value of a single parameter variation is

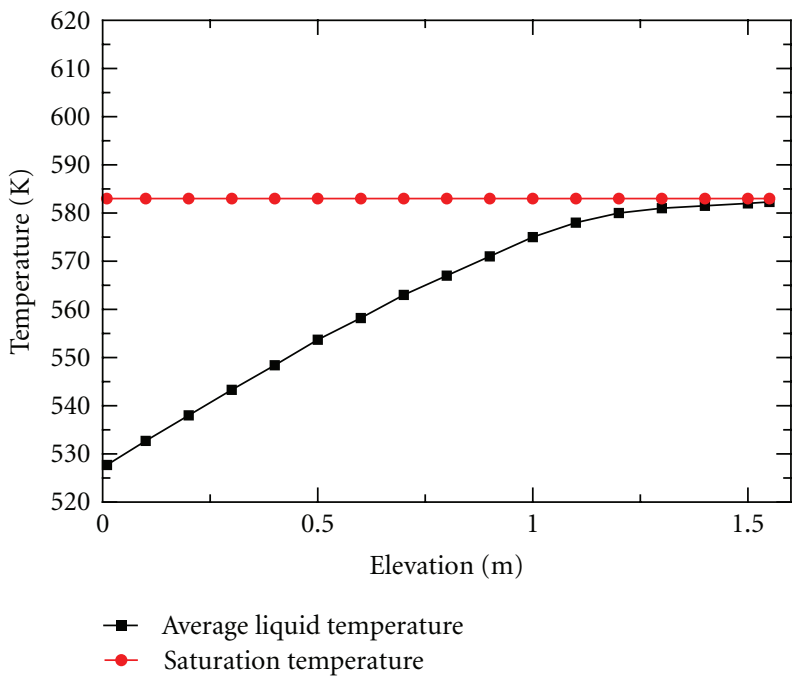

FIGURE 10: Run 1.4325: Longitudinal evolution of the average liquid temperature and of the saturation temperature.

more visible on the subcooled case, that is, the run that shows the lowest void-fraction value. Furthermore, it can be seen than within the bounds provided for the experimental uncertainties, no input parameter seems to have a foremost importance with respect to the others on the calculated void fraction.

As a second step, two additional series of calculations have been carried out: for each series, the set of parameters expected to give the highest or the lowest value of the averaged void fraction has been chosen. The results obtained are reported in Table 6. These simulations show that taking the two "opposite" sets of parameters give numerical results that may span on a range quite wide: for instance, for run 1.4325, the void-fraction value varies on a 0.08 -wide interval, representing approximately $15 \%$ of the nominal value. The impact is more visible for run 1.2211, where a calculated 0.03-wide variation represents nearly $50 \%$ of the nominal value.

\section{Effect of More Refined Descriptions of Bubble-Size Distribution}

The calculations presented so far have been obtained by using a constant and uniform predetermined bubble diameter equal to $0.3 \mathrm{~mm}$. In order to further investigate the five runs, simulations have been run by using dedicated models for 
TABLE 6: Calculated void-fraction values with two "opposite" sets of parameters.

\begin{tabular}{lccccc}
\hline & 1.2211 & 1.2223 & 1.2237 & 1.4325 & 1.4326 \\
\hline Exp. Values & 0.04 & 0.31 & 0.44 & 0.34 & 0.53 \\
Nominal Calc. values $\left(\alpha_{\text {nom }}\right)$ & 0.07 & 0.25 & 0.36 & 0.44 & 0.64 \\
\hline $\begin{array}{l}\text { Pressure }-1 \% \\
\text { Inlet Temp. }+1 \mathrm{~K}\end{array}$ & & & & & \\
Mass flow rate $-1.5 \%$ & 0.08 & 0.28 & 0.39 & 0.48 & 0.65 \\
Wall heat flux + $1 \%$ & & & & & \\
\hline $\begin{array}{l}\text { Pressure }+1 \% \\
\text { Inlet Temp. }-1 \mathrm{~K}\end{array}$ & & & & & \\
$\begin{array}{l}\text { Mass flow rate }+1.5 \% \\
\text { Wall heat flux }-1 \%\end{array}$ & 0.05 & 0.21 & 0.32 & 0.40 & 0.58 \\
\hline
\end{tabular}

the bubble-size distribution, namely, the model proposed by Yao and Morel [16], further referred to as the Yao-Morel model, and the model developed by Ruyer and co-workers $[17,19]$, further referred to as the Ruyer-Seiler model. The Yao-Morel model follows the so-called "single-size" approach for bubbly flows [20]. This approach considers that the bubbles have locally the same size, often represented by the Sauter mean diameter, which is directly connected to the local void fraction and to the interfacial area, the latter being obtained by the resolution of an additional transport equation. This equation takes into account bubblesize variation caused by gas compressibility, and contains terms standing for bubble coalescence and fragmentation that need to be modeled.

The Ruyer-Seiler model can be regarded as more refined since it follows the "moment-density" approach, which consists of assuming a certain form for the bubble diameter distribution function, and then solving equations on the moments defining this distribution. The Ruyer-Seiler model assumes a quadratic form for the bubble-diameter distribution whose graph extends from the origin and is consequently defined by only one parameter. Another possibility of postulated form for the bubble-diameter distribution is a log-normal law, as proposed for instance by Kamp and coworkers [21, 22].

In this section, we specifically focus on two runs: run 1.2211, whose conditions are the closest to PWR normal conditions, and run 1.4325, which exhibits an interesting void fraction distribution according to the experimental 2D view obtained by chromo-tomography.

6.1. Mesh Sensitivity Analysis. First, the two interfacial-area models have been applied on the three grid levels and for the five runs, to analyze the sensitivity of the results to the grid levels. The averaged void fractions obtained are summarized in Table 7, where it is shown that the discrepancy is of the order of 0.01 void-fraction units from grid level 1 to grid level 3, as it was the case for the computations with a fixed bubble diameter. Figures 11, 12 represent the longitudinal distribution of the averaged void fraction for the three grid levels for run 1.2211, and show that the mesh influence remains in the 0.01-limit in the whole domain.

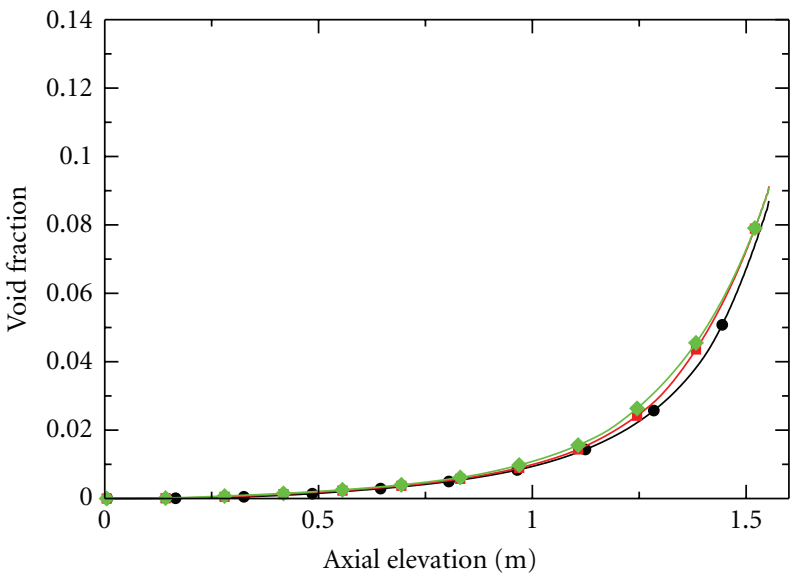

- Grid level 1
$\rightarrow$ Grid level 2
$\rightarrow \quad$ Grid level 3

FIGURE 11: Yao-Morel model: Grid influence on the void-fraction axial evolution for run 1.2211.

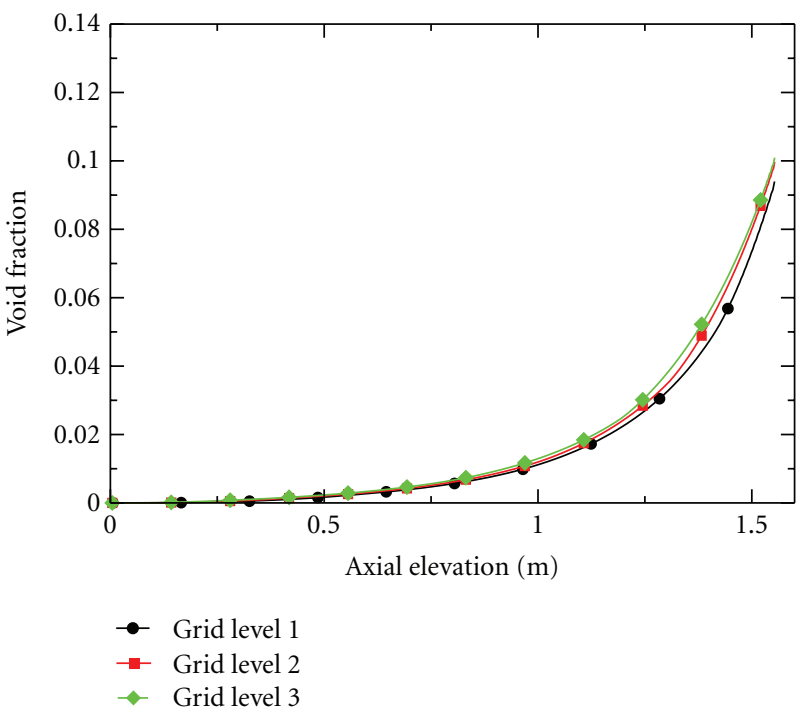

FIGURE 12: Ruyer-Seiler model: Grid influence on the void-fraction evolution for run 1.2211 .

6.2. Analysis of Run 1.2211 with Interfacial-Area Models. As shown in Figure 13, the behavior of the two bubble-size models is quite similar concerning the averaged void fraction: From the whole heated length, they predict a void fraction lower than the one obtained with a fixed bubble size. Besides, at the measuring section, the void fraction predicted by the models is closer the experimental value.

This underprediction with respect to the previous calculations can be connected to the size of the bubbles calculated by the models at the measuring section. The calculated average, minimum, and maximum size of the bubbles at the measuring section are summarized in Table 8. It can be observed that the mean bubble size calculated by the devoted models is smaller than the initial choice of $0.3 \mathrm{~mm}$ 
TABLE 7: Cross-section averaged void fraction obtained on the three grid levels for the two interfacial-area models used. Y-M stands for the Yao-Morel model; R-S stands for the Ruyer Seiler model.

\begin{tabular}{|c|c|c|c|c|c|c|c|c|c|c|}
\hline \multirow{3}{*}{$\begin{array}{l}\text { Exp. values } \\
\text { Bubble-size model }\end{array}$} & \multicolumn{2}{|c|}{1.2211} & \multicolumn{2}{|c|}{1.2223} & \multicolumn{2}{|c|}{1.2237} & \multicolumn{2}{|c|}{1.4325} & \multicolumn{2}{|c|}{1.4326} \\
\hline & \multicolumn{2}{|c|}{0.04} & \multicolumn{2}{|c|}{0.31} & \multicolumn{2}{|c|}{0.44} & \multicolumn{2}{|c|}{0.34} & \multicolumn{2}{|c|}{0.53} \\
\hline & Y-M & R-S & Y-M & R-S & Y-M & R-S & Y-M & R-S & Y-M & R-S \\
\hline Grid level 1 & 0.04 & 0.05 & 0.24 & 0.24 & 0.36 & 0.36 & 0.44 & 0.45 & 0.61 & 0.61 \\
\hline Grid level 2 & 0.05 & 0.05 & 0.24 & 0.24 & 0.36 & 0.36 & 0.44 & 0.45 & 0.61 & 0.61 \\
\hline Grid level 3 & 0.05 & 0.05 & 0.24 & 0.25 & 0.36 & 0.36 & 0.44 & 0.45 & 0.61 & 0.61 \\
\hline
\end{tabular}

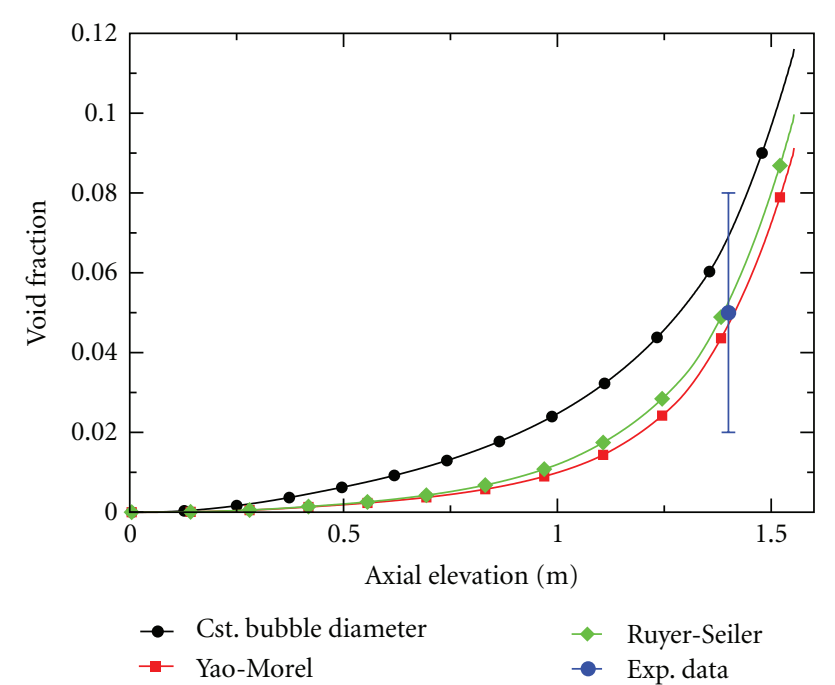

FIGURE 13: Comparison of calculated axial distribution of the mean void fraction for the bubble-size models.

TABLE 8: Run 1.2211. Characteristics of the bubble-diameter at the measuring section with different modeling choices.

\begin{tabular}{lccc}
\hline & Average & Minimum & Maximum \\
\hline Fixed bubble diameter & $0.3 \mathrm{~mm}$ & $0.3 \mathrm{~mm}$ & $0.3 \mathrm{~mm}$ \\
Yao-Morel model & $0.09 \mathrm{~mm}$ & $0.005 \mathrm{~mm}$ & $0.15 \mathrm{~mm}$ \\
Ruyer-Seiler model & $0.15 \mathrm{~mm}$ & $0.05 \mathrm{~mm}$ & $0.2 \mathrm{~mm}$ \\
\hline
\end{tabular}

used for the first calculation. This smaller size brings about an increase of the core-flow recondensation phenomenon (due to the higher interfacial area of smaller bubbles), and consequently a decrease of the void fraction.

Cross-section views of the bubble-diameter distributions at the measuring section are proposed in Figures 14, 15, showing quite a similar behavior; with the biggest bubbles (0.2 mm-diameter for the Ruyer-Seiler model, $0.15 \mathrm{~mm}$ for the Yao-Morel model) found above the heated walls, whereas the smallest are located in the center and the corners of the domain. To provide a detailed representation, the color scaling has been chosen as the most adapted for each case and is consequently not the same on the two figures.

6.3. Analysis of Run 1.4325 with Interfacial-Area Models. As can be seen in Table 7, the averaged void fraction for run 1.4325 obtained by using interfacial-area models is

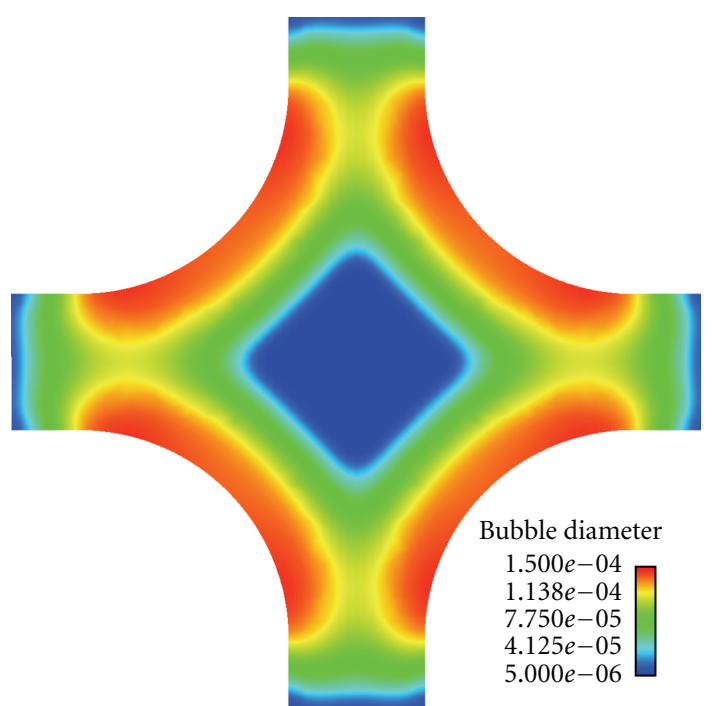

FIGURE 14: Bubble-diameter distribution at the measuring section for run 1.2211 by using the Yao-Morel model.

very similar to the one obtained with a fixed bubble-size diameter (of the order of 0.45 ). However, the void fraction distribution predicted by the three calculations present notable discrepancies, as presented by Figures 16, 17, and 18 (with a color scaling adapted to the case).

With a fixed bubble diameter set to $0.3 \mathrm{~mm}$, the void fraction is mostly concentrated in a thin layer adjacent to the heated wall, reaching locally peak values of approximately 0.85 and thus triggering the activation of the model of pseudo-film boiling, as described in Section 5.2. With dedicated bubble-size models, on the opposite, consider the following.

(i) The peak value of the void fraction predicted by applying the bubble-size models is quite lower $(0.65$ for the Yao-Morel model; 0.55 for the Ruyer-Seiler model). Lower void-fraction peak values calculated by the bubble-size models cause the flow to remain in the nucleate boiling remain for the whole elevation, as presented in Figure 19.

(ii) Besides, for these calculations (and especially with the Ruyer-Seiler model), high void-fraction values are found near the nonheated corners of the domain, phenomenon that can be seen on the experimental view. The effect of the lift force, which depends on 


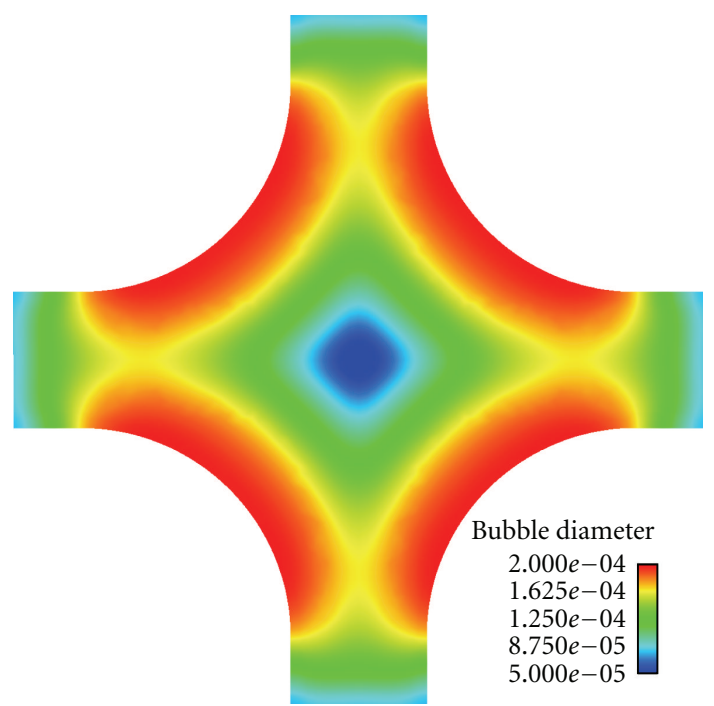

Figure 15: Bubble-diameter distribution at the measuring section for run 1.2211 by using the Ruyer-Seiler model.

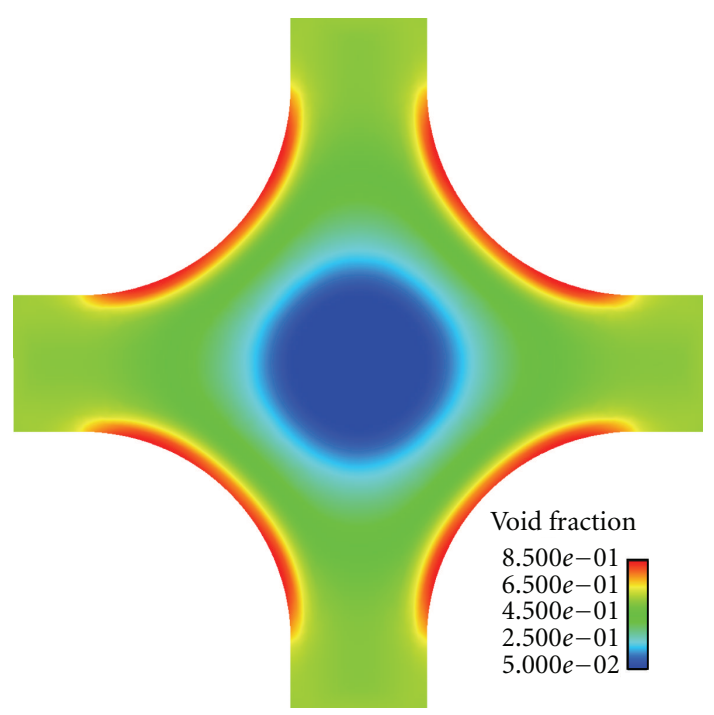

FIGURE 16: Void-fraction distribution at the measuring section for run 1.4325 with a fixed bubble diameter set to $0.3 \mathrm{~mm}$.

the bubble size, may account for this phenomenon, as the average bubble-size predicted by the Ruyer-Seiler model at the measuring section is approximately equal to $1 \mathrm{~mm}$, thus, very different from the calculations with a fixed bubble size. It should be noted that, even if the mean bubble diameter is different, the averaged void fraction is only slightly impacted since recondensation is very small in this case.

\section{Conclusion}

In this paper, we reported simulations with the multifield CFD code NEPTUNE_CFD in the framework of the first exercise of the OECD/NRC PSBT benchmark, which were

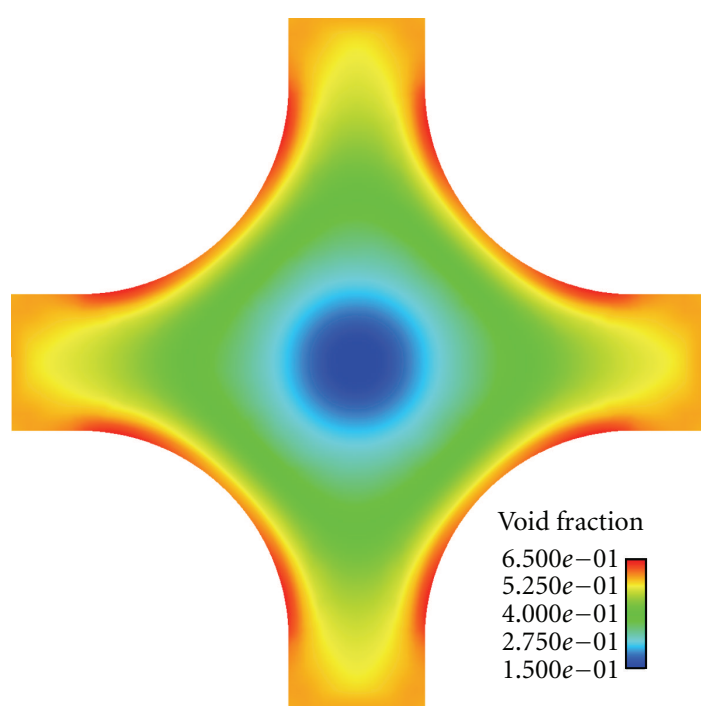

Figure 17: Void-fraction distribution at the measuring section for run 1.4325 by using the Yao-Morel model.

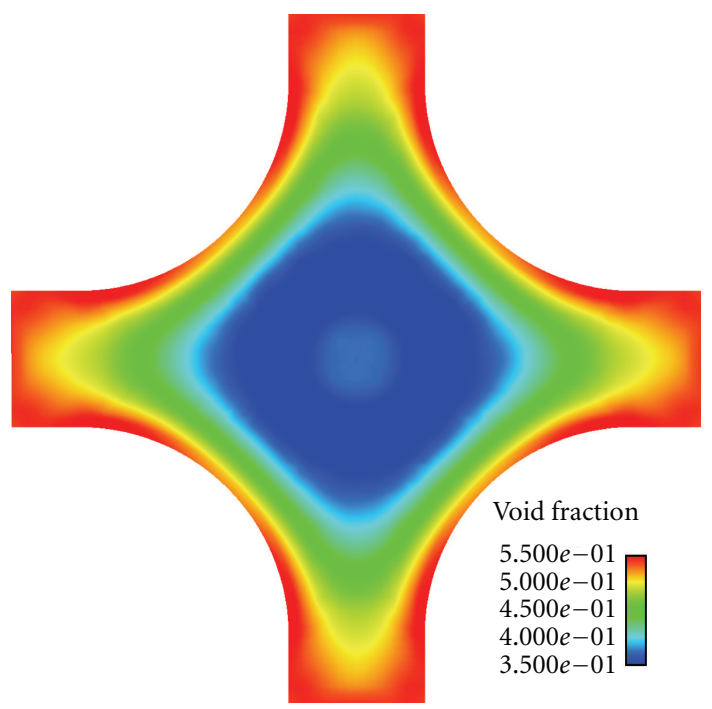

FIGURE 18: Void-fraction distribution at the measuring section for run 1.4325 by using the Ruyer-Seiler model.

carried out on a centered, isolated subchannel geometry and were compared to experimental data. A standard set of physical models was used, as well as a fixed bubble diameter. In nominal conditions, the discrepancy between calculated and experimental mean void fraction at the measurement section is on average of the order of \pm 0.06 void-fraction units. Following the NEA/CSNI best practice guidelines, the impact of the grid on the axial evolution of the mean void fraction has been investigated by using three grid levels, and shown to be of the order of 0.01 void-fraction units. Furthermore, a study of the numerical propagation of the experimental uncertainties has been carried out, providing an envelope of calculated void-fraction varying from 0.05 to 0.1 around the mean value. This sensitivity analysis could be 


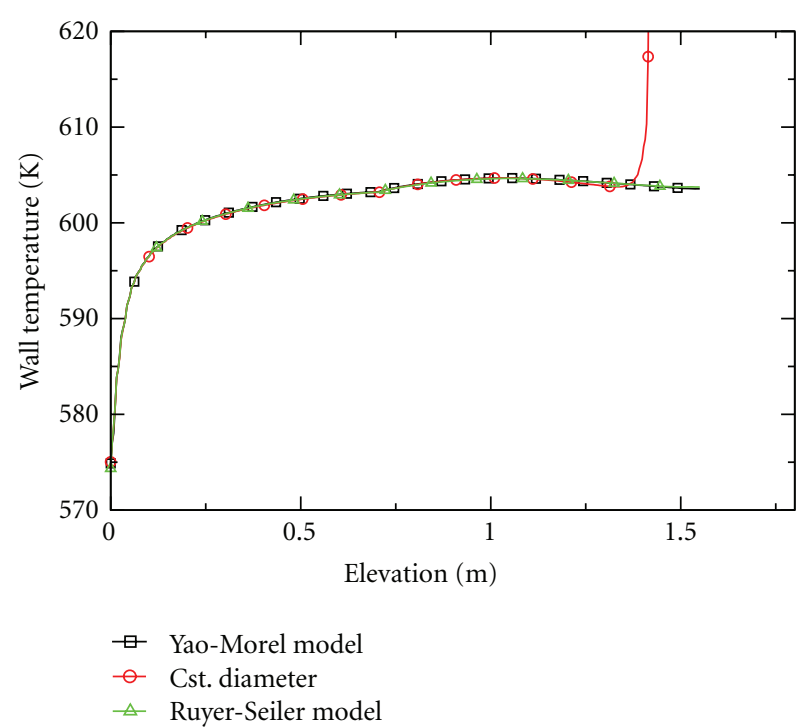

Figure 19: Evolution of the wall temperature at the probe position for different bubble-size models.

deepened by sampling all input parameters together, in order to study the coupling between these parameters.

As a second step, models allowing to simulate the dispersion in size of the bubbles have been applied. The use of these models impacted only slightly the axial evolution of the mean void fraction (of the order of 0.01 to 0.02 void-fraction units compared to the fixed-diameter calculation), and was more clearly seen on the subcooled run, with reduced difference between calculated and experimental averaged void fraction. Furthermore, for another run with a higher equilibrium quality, void-fraction distribution with bubblesize models is also shown to come closer to experiment. To further investigate the behavior of the different bubble-size models, as a future work, it would be relevant to study the difference between the break-up and coalescence terms in the two models. On a longer term, to improve the quality of the simulations of saturated (high void fraction) cases, novel methods are being developed in the NEPTUNE project which consider the simulation of large bubbles with interface locating technics, while keeping a statistical treatment for the smaller ones [23].

\section{Acknowledgments}

This work has been achieved in the framework of the NEPTUNE project, financially supported by CEA (Commissariat à l'Énergie Atomique et aux Énergies Alternatives), EDF, IRSN (Institut de Radioprotection et de Sûreté Nucléaire), and AREVA-NP.

\section{References}

[1] PSBT page on the OECD website. July 2012, http://www.oecdnea.org/science/wprs/egrsltb/PSBT.

[2] A. Guelfi, D. Bestion, M. Boucker et al., "NEPTUNE: a new software platform for advanced nuclear thermal hydraulics,"
Nuclear Science and Engineering, vol. 156, no. 3, pp. 281-324, 2007.

[3] Nuclear Energy Agency-Committee on the Safety of Nuclear Installations, "Best practice guidelines for the use of CFD in nuclear reactor safety applications," Technical Report NEA/CSNI, 2007.

[4] K. Hori, Y. Akiyama, K. Miyazaki, T. Kurosu, and S. Sugiyama, "Void Fraction in a single channel simulating one subchannel of a PWR fuel assembly," in Two-Phase Flow Modelling and Experimentation, G. P. Celata and R. K. Shah, Eds., vol. 1, ETS edition, 1995.

[5] K. Hori, K. Miyazaki, T. Kurosu, S. Sugiyama, J. Matsumoto, and Y. Akiyama, "In bundle void fraction measurement of PWR fuel assembly," in Proceedings of the 2nd ASME/JSME Nuclear Engineering Joint Conference, F. Peterson, Ed., vol. 1, March 1993.

[6] P. Coste, J. Pouvreau, C. Morel, J. Laviéville, M. Boucker, and A. Martin, "Modeling turbulence and friction around a large interface in a three-dimension two-velocity eulerian code," in Proceedings of the 12th International Topical Meeting on Nuclear Reactor Thermal Hydraulics (NURETH '12), Pittsburgh, Pa, USA, October 2007.

[7] M. Ishii, Thermo-Fluid Dynamic, Theory of Two-Phase, Eyrolles, 1975.

[8] N. Méchitoua, M. Boucker, J. Laviéville, J. M. Hérard, S. Pigny, and G. Serre, "An unstructured finite volume solver for two phase water/vapour flows based on an elliptic oriented fractional step method," in Proceedings of the 10th International Topical Meeting Nuclear Reactor Thermal Hydraulics (NURETH '10), Seoul, Republic of Korea, 2003.

[9] S. Mimouni, F. Archambeau, M. Boucker, J. Lavieville, and C. Morel, "A second order turbulence model based on a Reynolds stress approach for two-phase boiling flow. Part 1: Application to the ASU-annular channel case," Nuclear Engineering and Design, vol. 240, no. 9, pp. 2233-2243, 2010.

[10] M. Lance and M. L. de Bertodano, "Phase distribution phenomena and wall effects in bubbly two-phase flows," Multiphase Science and Technology, vol. 8, pp. 69-123, 1994.

[11] M. Ishii and N. Zuber, "Drag coefficient and relative velocity in bubbly, droplet or particulate flows," AIChE Journal, vol. 25, no. 5, pp. 843-855, 1979.

[12] N. Zuber, "On the dispersed two-phase flow in the laminar flow regime," Chemical Engineering Science, vol. 19, no. 11, pp. 897-917, 1964.

[13] A. Tomiyama, H. Tamai, I. Zun, and S. Hosokawa, "Transverse migration of single bubbles in simple shear flows," Chemical Engineering Science, vol. 57, no. 11, pp. 1849-1858, 2002.

[14] N. Kurul and M. Podowski, "Multidimensional effects in forced convection subcooled boiling," in Proceedings of the 9th International Heat Transfer Conference, vol. 1, p. 21, Jerusalem, Israel, 1990.

[15] S. Mimouni, F. Archambeau, M. Boucker, J. Lavieville, and C. Morel, "A second order turbulence model based on a Reynolds stress approach for two-phase boiling flow and application to fuel assembly analysis," Nuclear Engineering and Design, vol. 240, no. 9, pp. 2225-2232, 2010.

[16] W. Yao and C. Morel, "Volumetric interfacial area prediction in upward bubbly two-phase flow," International Journal of Heat and Mass Transfer, vol. 47, no. 2, pp. 307-328, 2004.

[17] P. Ruyer, N. Seiler, M. Weiss, and F. P. Weiss, "A bubble size distribution model for the simulation of bubbly flows," in Proceedings of the 6th International Conference on Multiphase Flows, Leipzig, Germany, 2007. 
[18] J. G. Collier and J. R. Thome, Convective Boiling and Condensation, Oxford Science, 3rd edition, 1994.

[19] N. Seiler and P. Ruyer, "Advanced model for polydispersion in size in boiling flows," in 190ème Session Du Comité Scientifique Et Technique De La Société HydroTechnique De France : Modélisation Des Écoulements Diphasiques bouilLants, 2008.

[20] T. Hibiki and M. Ishii, "One-group interfacial area transport of bubbly flows in vertical round tubes," International Journal of Heat and Mass Transfer, vol. 43, no. 15, pp. 2711-2726, 2000.

[21] A. M. Kamp, Ecoulements turbulents à bulles dans une conduite en micropesanteur [Ph.D. thesis], Institut National Polytechnique de Toulouse, 1996.

[22] A. M. Kamp, A. K. Chesters, C. Colin, and J. Fabre, "Bubble coalescence in turbulent flows: a mechanistic model for turbulence-induced coalescene applied to microgravity bubbly pipe flow," International Journal of Multiphase Flow, vol. 27, no. 8, pp. 1363-1396, 2001.

[23] R. Denèfle, S. Mimouni, J. P. Caltagirone, and S. Vincent, "Multifield hybrid approach from bubble to slug flow transition modelling," in Advances in Fluid Mechanics IX, M. Rahman and C. A. Brebbia, Eds., WIT, 2012. 

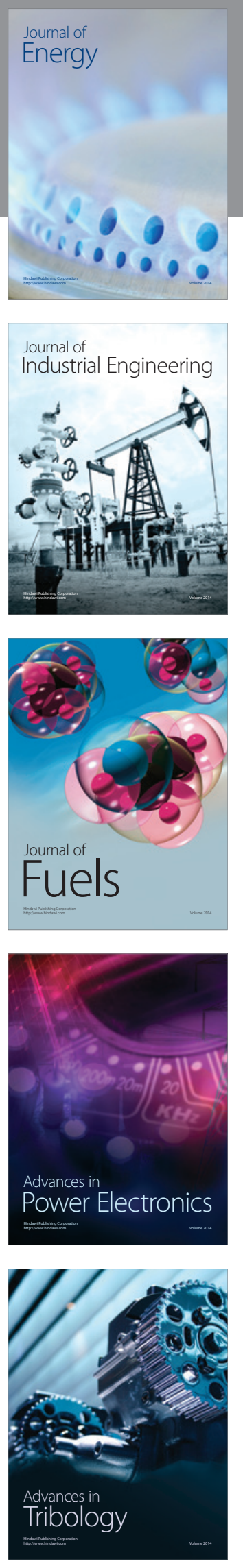
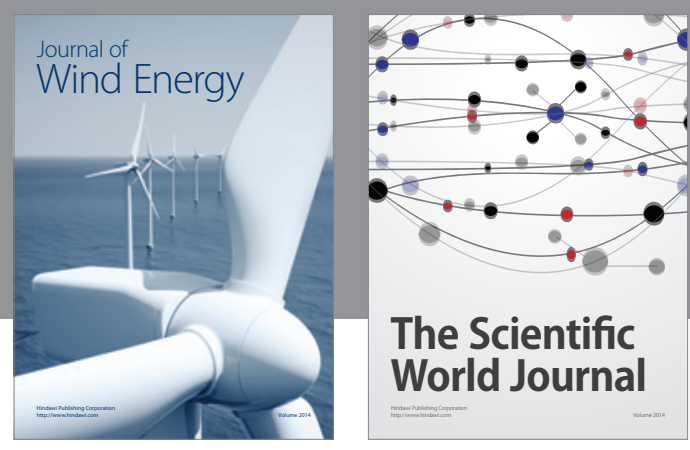

The Scientific World Journal

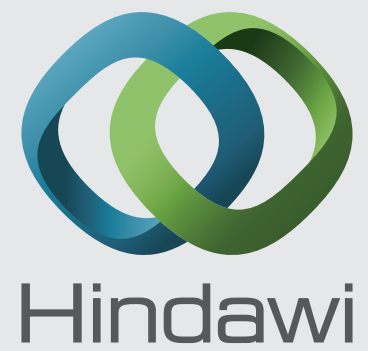

Submit your manuscripts at http://www.hindawi.com
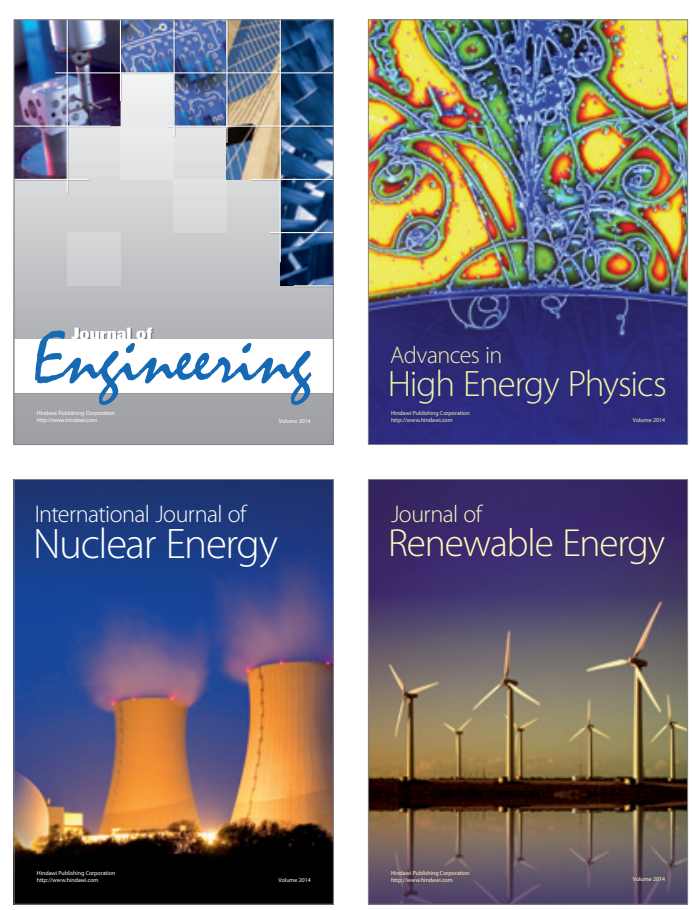

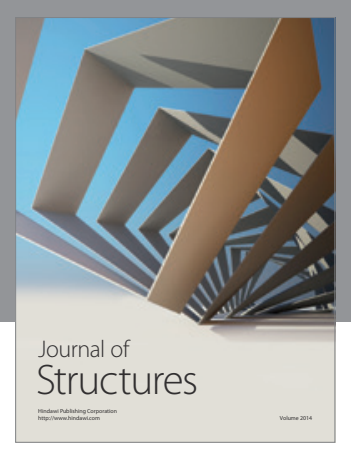

Rotating
Mechinery
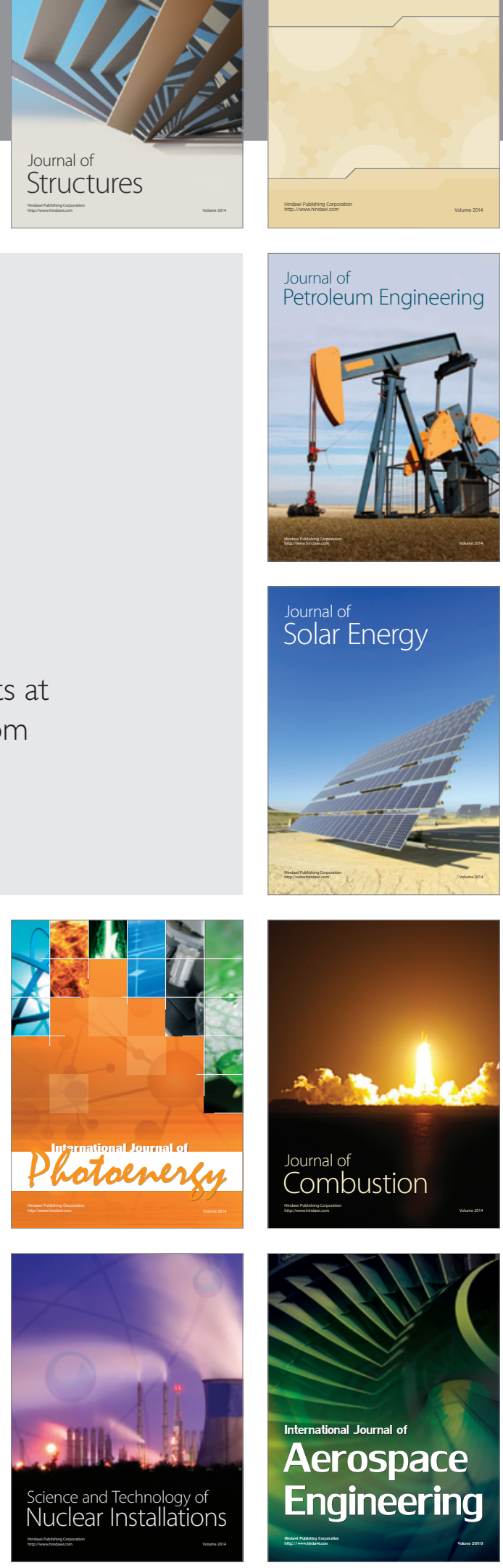